\title{
AN INNOVATIVE DEVICE FOR THE MECHANICAL TESTING OF MINIATURE SPECIMENS OF SUPERALLOYS
}

\author{
B Roebuck ${ }^{1}$, D C Cox ${ }^{2}$ and R C Reed ${ }^{3}$ \\ ${ }^{1}$ Materials Centre, National Physical Laboratory, Teddington, UK \\ ${ }^{2}$ Department of Electronic Engineering, The University of Surrey, Guildford, UK \\ ${ }^{3}$ Department of Metals and Materials Engineering, The University of British Columbia, Vancouver, Canada
}

\begin{abstract}
A new miniature test system has been used to investigate the high temperature mechanical and physical characterics of superalloys. Different types of mechanical test - static and dynamic loading and multihit tests were used to follow softening during recrystallisation at high temperature. The kinetics of recrystallisation were studied by analyzing the recovery of strength in multihit elevated temperature tests through calculations of apparent activation energy. Measurements of resistivity were used, in addition, to throw light on the internal microstructural state of the alloys.
\end{abstract}

\section{Introduction}

The characterisation of the mechanical behaviour of superalloys is important but also tremendously difficult, for various reasons. First, data are often required at very high temperatures - often close to the melting point - so that the design of grips, extensometers, etc is challenging. Moreover, the acquisition of mechanical data using conventional methods is often costly and time-consuming. Second, the alloys themselves are expensive and often only limited quantities are available, especially during the prototyping of new grades of alloy. Finally, the superalloys are often used in thin sections; the wall thicknesses of a modern cooled turbine blade are often just a few millimetres, for example. This leads to several questions. Should one then expect the properties to differ from those exhibited by larger sections? And at these wall thicknesses, how to evaluate the degradation of turbine blading after service exposure, so that the remaining life can be estimated? Such issues are important as attempts are made to reduce life cycle costs, with greater emphasis being placed on the refurbishment of gas turbine parts.

With these concerns in mind, an innovative testing system has been designed which is capable of testing miniature testpieces with cross-sections as small as $1 \mathrm{~mm}^{2}$, at elevated temperatures, especially above $1000{ }^{\circ} \mathrm{C}$. The new system, by using the principle of miniaturisation, overcomes many of the limitations identified above, although there remains some concern over the validity of the data due to the smaller size of the testpiece and the novel strain measurement system. Previous work using this system has demonstrated its usefulness for assessing the temperature dependence of $\gamma^{\prime}$ volume fraction ${ }^{1}$ and recrystallisation in the CMSX-4 Ni-base superalloy ${ }^{2}$. In this paper, the results from our most recent studies are reported.

\section{$\underline{\text { Test System }}$}

The miniature electro-thermomechanical test system (the ETMT) has been developed at the National Physical Laboratory to obtain multiproperty data over a range of temperatures. The system uses DC electric current to heat rectangular cross section testpieces, water cooling for the test-piece grips, a facility for inert gas supply to prevent sample oxidation, and full computer-control and digital data acquisition. In the present arrangement, strain is deduced by monitoring changes in resistance. Both thermal and mechanical loads can be cycled.

The ETMT can perform experiments with experimental objectives that can be categorised into three types

- Measurement of physical properties, such as thermal expansion and conductivity

- Measurement of mechanical properties, such as creep, fatigue and strength

- Measurement of microstructural stability under thermal exposure, such as recrystallisation, and phase transformation.

The ETMT consists of an environmental chamber $(500 \times 250 \times$ $120 \mathrm{~mm}$ ) with electrical leadthroughs, with an integral testpiece resistance and thermocouple measurement facility. Testpiece geometries are determined by testpiece resistance. Metallic testpieces, are typically $2 \times 1 \mathrm{~mm}$ cross section along the full length of the testpiece $(40 \mathrm{~mm})$. The gripped ends are typically 10-15 mm long leaving a freely suspended central portion of $10-20 \mathrm{~mm}$, Fig 1. Heating rates up to $200{ }^{\circ} \mathrm{C} \mathrm{s}^{-1}$ are possible, dependent on the thermal characteristics of the testpiece. Cooling rates are determined by the thermal diffusivity of the testpiece and loss of heat to grips. This can typically be between $100{ }^{\circ} \mathrm{C} \mathrm{s}^{-1}$ or $10{ }^{\circ} \mathrm{C} \mathrm{s}^{-1}$ for good and poor conductors, respectively. The testpiece grips are held at a fixed temperature (room temperature) to provide a constant reference point. This results in a parabolic temperature distribution for testpieces smaller than about $20 \mathrm{~mm}$ in length with a central temperature up to $800{ }^{\circ} \mathrm{C}$. Temperature distributions in testpieces heated to much higher temperatures are more uniform in the central 2-4 $\mathrm{mm}$ of the testpiece, typically less than $\pm 5{ }^{\circ} \mathrm{C}$ at a central temperature of $1250{ }^{\circ} \mathrm{C}$. The system uses a mechanical loading assembly ( $\pm 3 \mathrm{kN}$ maximum), with an in-line drive and a versatile gripping system, a load cell $(0.5 \mathrm{~N}$ resolution $)$ and capacitance displacement transducers $(0.4$ micrometre resolution). A computer-controlled motor is included for null, mean, ramping or fatigue load capability (in or out-of-phase DC current cycle) or constant displacement tests for stress relaxation or thermal shock experiments. Uniaxial tests can have variable loading rates, typically $0.1-20 \mathrm{~N} \mathrm{~s}^{-1}$. Full thermo-mechanical 
control is possible in load or displacement control modes with options for sinusoidal, triangular, trapezoidal or arbitrary waveforms for both load and temperature, together with any degree of phase lag. Full strain control is not yet possible due to the difficulty of strain measurement on such small testpieces, although an optical system for this purpose is in development. The system uses customised LabView ${ }^{\circledR}$ software to monitor and control tests and temperature cycles by appropriate feedback control.

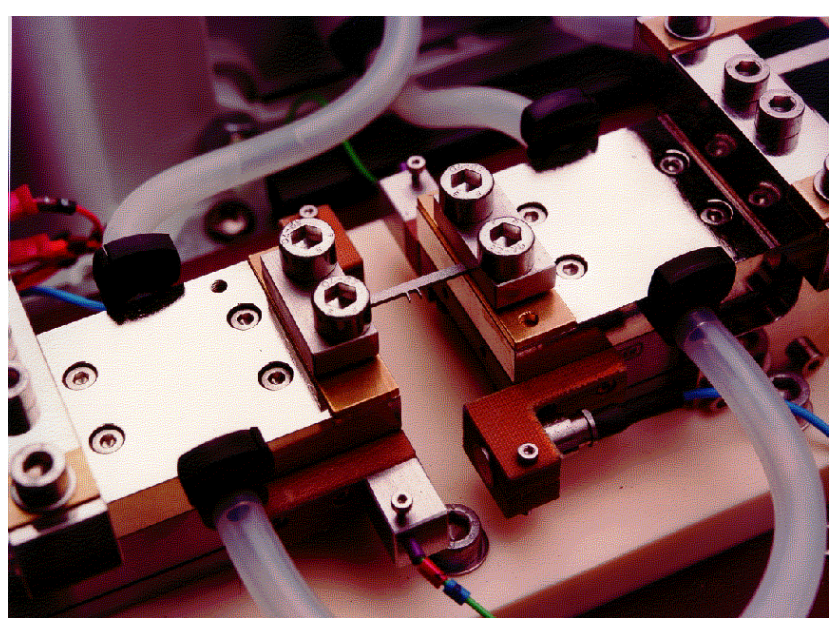

Fig 1 Close-up photograph of testpiece and grips.

\section{$\underline{\text { Temperature Measurement and Distribution }}$}

Because the testpiece is held in water cooled grips a non-uniform temperature distribution develops along the testpiece. Measurements and analysis have shown that the steady state temperature profile along the testpiece is parabolic at temperatures up to about $800{ }^{\circ} \mathrm{C}$. The program software maintains control of temperature even if the testpiece changes in cross section, providing the strain rate is not greater than about $0.01 \mathrm{~s}^{-1}$. For uniaxial tests the loading rate can be set at rates between $0.05 \mathrm{~N}$ $\mathrm{s}^{-1}$ to $1000 \mathrm{~N} \mathrm{~s}^{-1}$. During the test, changes in length are monitored by the capacitance transducers mounted on the grips and results are plotted as load against displacement. However, it must be noted that the displacement contains an element due to the compliance of the rig which is about $0.05 \mu \mathrm{m} \mathrm{N} \mathrm{N}^{-1}$. Samples typically fracture and deform in the central region which acts rather like a reduced cross section in a conventional test because the material is softer in this part of the testpiece.

A further issue is the accuracy of temperature measurement, since thermocouples are made at NPL individually for each test, using $0.1 \mathrm{~mm}$ diameter wires of $\mathrm{Pt}$ and $\mathrm{Pt}-13 \% \mathrm{Rh}$, that are fusion welded to form a small bead. The bead is then spot welded to the testpiece. Furthermore the voltage is processed by a standard LabView $^{\circledR}$ software routine to give a direct reading in ${ }^{\circ} \mathrm{C}$. A sample of pure Ti was used in order to check the combined ETMT software and thermocouple. Ti has a well defined transformation temperature. Repeat measurements were made and the indicated temperature of the transformation was with $2{ }^{\circ} \mathrm{C}$ of the handbook value for pure Ti.

\section{$\underline{\text { Strain Measurement }}$}

Because of the difficulties of deconvoluting the load/displacement data from rig compliance and with a temperature distribution, an alternative strain measurement procedure was developed based on the use of resistance measurements. Resistance is measured over the central $2-3 \mathrm{~mm}$ of the testpiece, where the temperature distribution is reasonably constant, using thin, $0.1 \mathrm{~mm}$, spot welded Pt-13\% Rh wires as potential contacts. Due to the change in the cross sectional area during a deformation test the resistance in the central 2-3 $\mathrm{mm}$ of the testpiece changes significantly. The resistance increases in tension and decreases in compression. The following analysis was developed to allow true stress/strain data to be obtained from these changes. The resistance before and during deformation, $\mathrm{R}_{\mathrm{s}}$ and $\mathrm{R}_{\mathrm{t}}$, are given by

$$
\mathrm{R}_{\mathrm{s}}=\mathrm{rL}_{\mathrm{s}} / \mathrm{w}_{\mathrm{s}} \mathrm{h}_{\mathrm{s}} \text { and } \mathrm{R}_{\mathrm{t}}=\mathrm{rL}_{\mathrm{t}} / \mathrm{w}_{\mathrm{t}} \mathrm{h}_{\mathrm{t}}
$$

where $\mathrm{r}$ is the resistivity, $\mathrm{L}$ is the length between the contact points for measuring resistance and $\mathrm{w}$ and $\mathrm{h}$ are the width and height of the testpiece. Assuming that the volume, V, remains constant, and neglecting elastic changes

$$
\mathrm{V}_{\mathrm{s}}=\mathrm{V}_{\mathrm{t}}=\mathrm{L}_{\mathrm{s}} \mathrm{w}_{\mathrm{s}} \mathrm{h}_{\mathrm{s}}=\mathrm{L}_{\mathrm{t}} \mathrm{w}_{\mathrm{t}} \mathrm{h}_{\mathrm{t}}
$$

Consequently

$$
\mathrm{R}_{\mathrm{s}} / \mathrm{R}_{\mathrm{t}}=\mathrm{L}_{\mathrm{s}}^{2} / \mathrm{L}_{\mathrm{t}}^{2}
$$

Thus, true strain, $\varepsilon$, is given by

$$
\varepsilon=\ln \left(\mathrm{L}_{\mathrm{t}} / \mathrm{L}_{\mathrm{s}}\right)=\ln \sqrt{\left(\mathrm{R}_{\mathrm{t}} / \mathrm{R}_{\mathrm{S}}\right)}
$$

which is a simple expression allowing strain to be calculated as a function of the measured change in resistance.

\section{Applications}

A range of applications of the system are described to illustrate the versatility of the instrument to provide data that will underpin an improved understanding of the mechanical behaviour at elevated temperatures of the superalloys, including

- Flow stress measurements

- Resistivity experiments

- $\quad$ Oxidation and pyrometry

- Recrystallisation kinetics.

\section{Flow Stress Measurements}

To address the concern of reproducibility, experiments were conducted using the miniature test system to obtain mechanical data on the Ni-base alloy, IN718, which could be compared with a recent review of the high temperature strength of this material ${ }^{3}$. The miniature test data was obtained by heating the testpiece to a suitable temperature (in the range $950-1200^{\circ} \mathrm{C}$ ) then applying a constant stress (in the range 5-100 $\mathrm{MPa}$ ) and measuring the resulting strain rate (which was more or less constant after a small primary region). Strain was calculated from changes in resistance of the sample ${ }^{4}$. The results obtained using the miniature system are shown in Fig 2 where stress is plotted against the ZenerHollomon parameter (obtained using an activation energy of $300 \mathrm{~kJ} \mathrm{~mole}^{-1}$ ). The solid bold line is the best fit to the 
Lewandowski and Overfelt data. This is extended with a fainter line to lower values of applied stress. It can be seen that the data from the miniature system agree extremely well with this best fit over a wide range of stress and temperature. It must be remembered that all the results were obtained on a single small sample tested over a period of 2-3h. The data at the highest temperatures were obtained first of all. Clearly there is little history dependence (the material is not work hardening/softening) in the results from these mechanical tests.

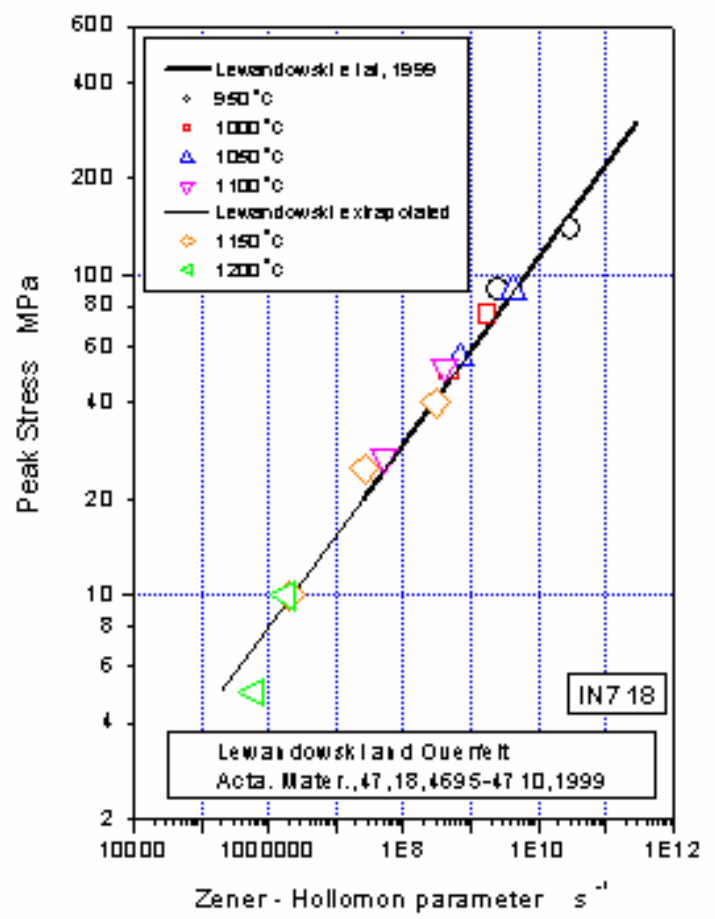

Fig 2 Comparison of ETMT and literature data on IN718.

Particularly for numerical modelling activities which play a crucial role in designing superalloys with appropriate microstructures, data are needed which describe accurately the mechanical behaviour of single crystal superalloys close to their melting point. In further experiments, specimens of CMSX-4 were tested in tension and compression (usually in pairs of tests; compression to a few $\%$ - say about 3 to $5 \%$ - followed by tension to the same strain to regenerate the original geometry) at a range of temperatures and deformation rates. Typical stress/strain curves obtained in tests at $1250{ }^{\circ} \mathrm{C}$ are shown in Fig 3. There is some evidence that compressive strength values are higher than those in tension. The stress $(\sigma) /$ strain $(\varepsilon)$ data were analysed either by taking the value of flow stress at a specified strain or using an expression of the type

$$
\sigma=\sigma_{\mathrm{o}}+\left(\sigma_{\mathrm{p}}-\sigma_{\mathrm{o}}\right)(1-\exp (\mathrm{a} \varepsilon))^{0.5}
$$

where $\sigma_{\mathrm{o}}$ is a yield strength, $\sigma_{\mathrm{p}}$ is a peak strength and a is a constant dependent on deformation parameters. The $\sigma_{\mathrm{p}}$ values in tension were plotted against strain rate (Fig 4) following the Zener-Hollomon expression

$$
\mathrm{F}(\sigma)=\mathrm{A} \dot{\varepsilon} \exp [\beta / \mathrm{T}]
$$

where A is a constant, $\mathrm{F}(\sigma)$ is a function of the peak flow stress and $\beta$ is a parameter related to the activation energy, giving an effective activation energy of about $480 \mathrm{~kJ} / \mathrm{mol}$ in this temperature range.

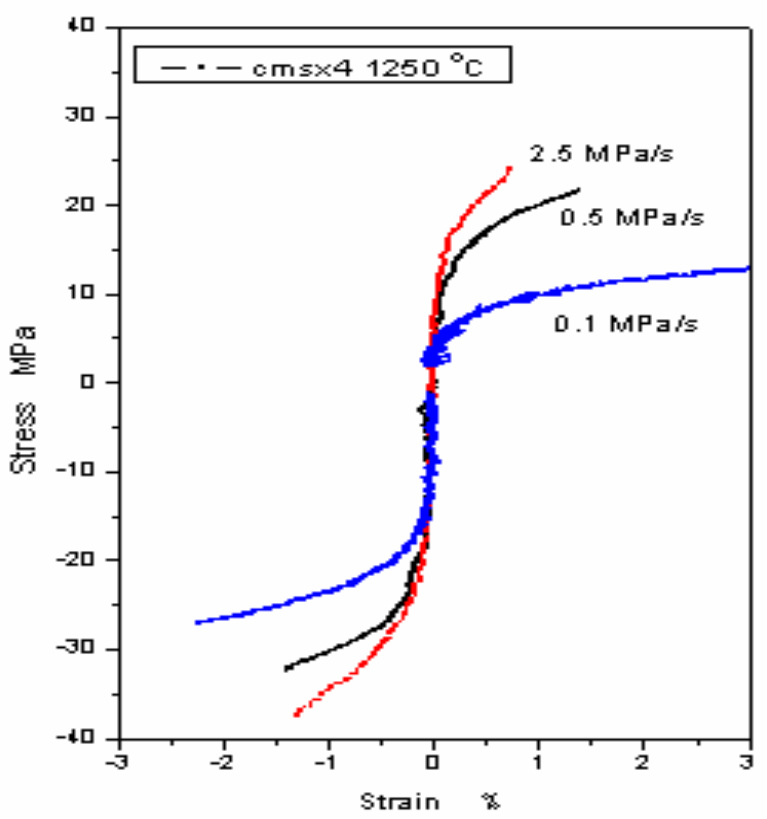

Fig 3 Effect of deformation rate on stress/strain response of CMSX-4 at $1250^{\circ} \mathrm{C}$.

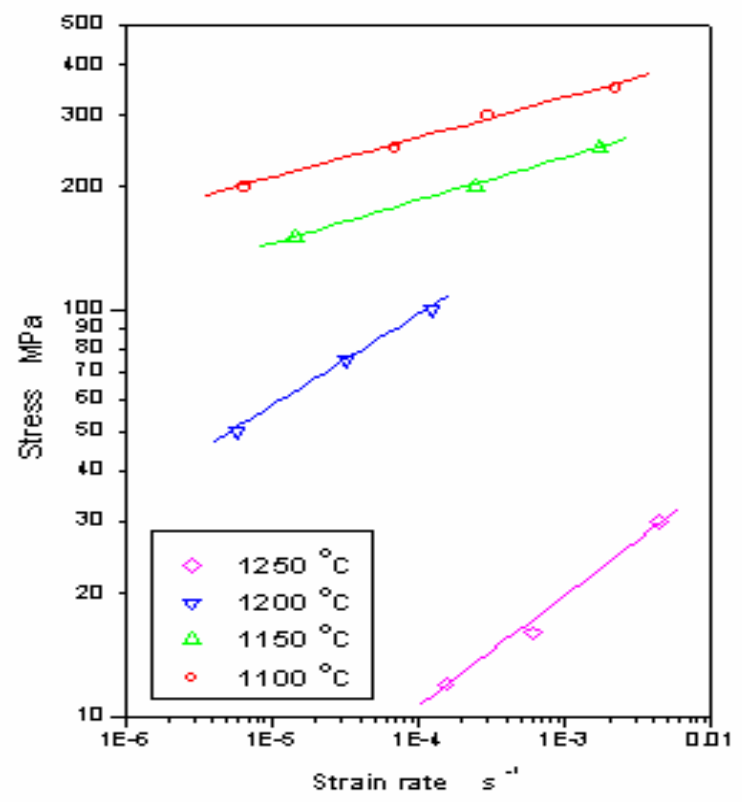

Fig 4 CMSX-4 flow stress dependence on temperature and strain rate. 


\section{$\underline{\text { Resistivity measurements }}$}

It is important to evaluate the value of the solidus temperature when conducting high temperature mechanical tests so that tests are conducted in a wholly solid region. For this purpose resistivity measurements were used. The dependence of CMSX-4 resistivity on temperature is shown in Fig 5 showing the rapid increase in resistivity that occurs at the solidus temperature (about $1350{ }^{\circ} \mathrm{C}$ in this alloy) on the formation of a liquid phase.

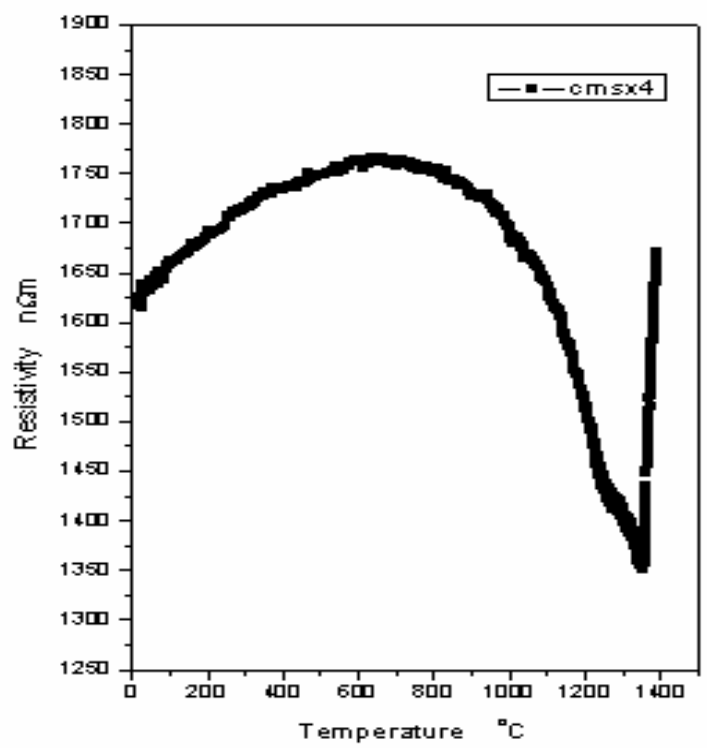

Fig 5 Dependence of resistivity on temperature for CMSX4.

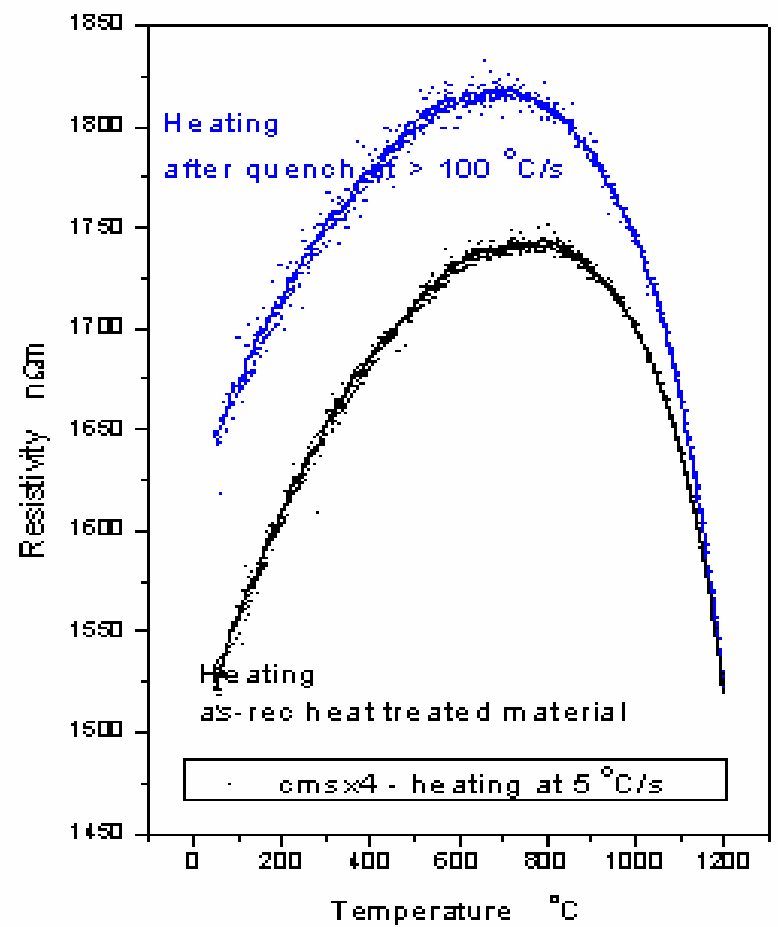

Fig 6 Effect of heat treatment on resistivity curves.
Figure 5 also shows the fall in resistivity above about $800{ }^{\circ} \mathrm{C}$ that is caused by dissolution of the $\gamma^{\prime}$ precipitate. The shape of this curve can be altered through different heat treatments as can be seen in Fig 6, which shows the resistivity curve on heating at $5{ }^{\circ} \mathrm{C} / \mathrm{s}$ for the as received heat-treated material compared with that for the same sample after quenching at greater than $100{ }^{\circ} \mathrm{C} / \mathrm{s}$. This process results in a much finer $\gamma^{\prime}$ precipitates and possible different matrix solution chemistry that gives a higher value of resistivity and shifts the dissolution curve to slightly lower temperatures.

\section{Oxidation and pyrometry measurements}

Measurement of temperature is a crucial parameter in test procedures that generate data for modeling. Methods of temperature measurement generally include either thermocouples or pyrometers. The early stages of oxide growth can cause interference effects that result in large variations in apparent temperature when pyrometers are used. Typical examples are shown in Figs 7 and 8 in tests on IN718 and Nimonic 90 at $850{ }^{\circ} \mathrm{C}$. In the experiment the temperature, as indicated by the thermocouple, was held constant. It can be seen that the temperature determined by pyrometry showed large differences, sometimes more than $\pm 100{ }^{\circ} \mathrm{C}$, from that indicated by the thermocouple. The characteristic times of the first minimum and first maximum $\left(\mathrm{C}_{\mathrm{t}_{2}}\right.$ and $\mathrm{C}_{\mathrm{t}_{3}}$ in Fig 7 ) are assumed to correspond to a certain oxide film thickness.

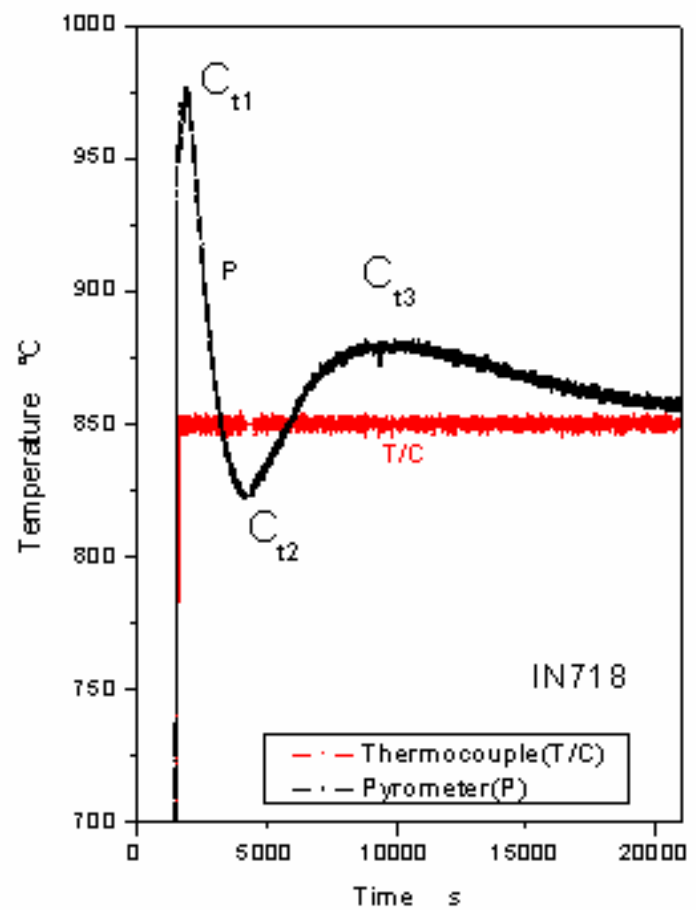

Fig 7 Comparison of pyrometer and thermocouple temperature showing characteristic times in experiment on IN718 at $850^{\circ} \mathrm{C}$. 
For the ETMT pyrometer experiments, assuming a parabolic oxidation law and where the measured parameter is a characteristic time to a fixed film thickness, $\lambda$, then

$$
\lambda=\mathrm{K} \sqrt{\mathrm{t}}
$$

where $\mathrm{K}$ is the rate constant and $\mathrm{t}$ is time.

Therefore, for experiments at different temperatures, $\mathrm{K}$ is an Arrhenius function of temperature, $\mathrm{T}$, and so

$$
\lambda=\mathrm{K}_{\mathrm{o}} \exp \left[\frac{-\mathrm{Q}}{\mathrm{RT}}\right] \sqrt{\mathrm{t}}
$$

Therefore, at constant $\lambda$, a plot of $\ln \left(1 / \sqrt{\mathrm{C}_{\mathrm{t}}}\right)$ vs $1 / \mathrm{T}$ can be used to obtain a value for Q (Fig 9). A set of experiments was conducted on Nimonic 90 at different temperatures (Fig 9) and the slopes indicate an activation energy of $163 \mathrm{~kJ} / \mathrm{mol}$. Thus the pyrometer data is consistent with reported activation energies for $\mathrm{Al}_{2} \mathrm{O}_{3}$ and $\mathrm{Cr}_{2} \mathrm{O}_{3}$ scaling processes in $\mathrm{Ni}$ base alloys ${ }^{6}$. These observations are of significance to the materials testing community because the duration of mechanical tests often does not allow a stable surface condition to develop. It is important therefore to characterize each material type if pyrometers are to be used with confidence.

\section{$\underline{\text { Recrystallisation Kinetics }}$}

Recrystallisation kinetics were evaluated using the multihit method ${ }^{\mathbf{5}}$. In this test method a CMSX4 testpiece was deformed to about $5 \%$ strain, at a relatively low temperature, about $1100{ }^{\circ} \mathrm{C}$. The testpiece was then heated to a higher temperature and small loads were applied at constant deformation rates, to the point the sample just yielded - then unloaded, after various time periods. A plot of yield (arbitrarily defined) stress against the log of time is shown in Fig 10. The drop in stress is assumed to be a result of recrystallisation and the kinetics of the process can be obtained from the temperature and time dependence of the yield stress drops. This is shown in Fig 11 where the flow stress values from the multihit tests are plotted against the inverse temperature for $\log t$ values of 2, 3 and 4 (from Fig 10). The average slope gives an effective activation energy of $516 \mathrm{~kJ} / \mathrm{mol}$, which is quite similar to that obtained from the deformation tests.

\section{Summary}

The versatility of a new miniature test system to investigate the high temperature mechanical and physical characterisation of superalloys has been demonstrated through different types of mechanical test - static and dynamic loading, oxidation and resistivity experiments, and multihit tests to follow softening during recrystallisation at high temperature. The kinetics of recrystallisation appear to be controlled by a similar mechanism to that influencing flow stress behaviour at temperatures greater than $1200{ }^{\circ} \mathrm{C}$. It is also shown that measurements of resistivity can provide useful insight into the internal microstructural state of the alloys, and that particular care must be taken if pyrometers are used to measure temperature.

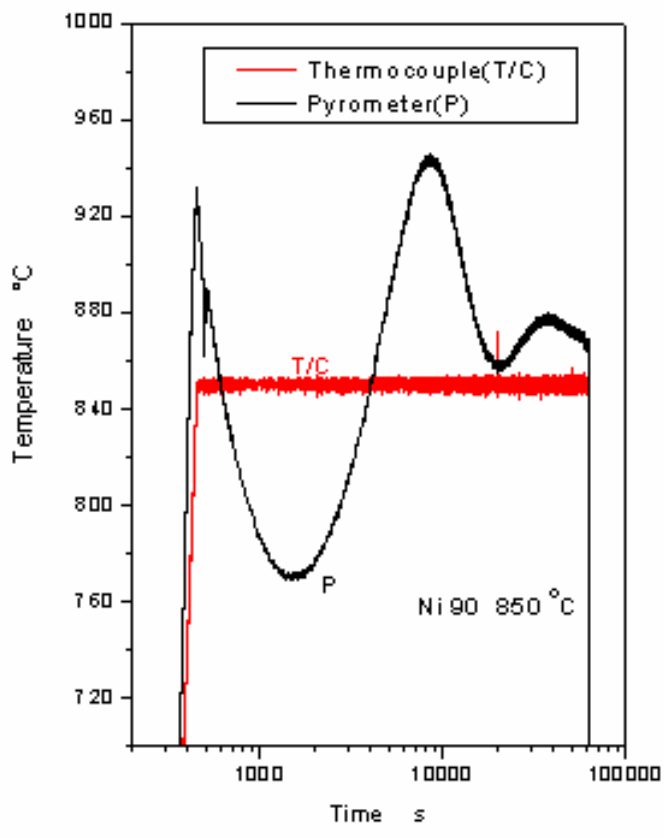

Fig 8 Comparison of pyrometer and thermocouple temperatures for Nimonic 90 at $850^{\circ} \mathrm{C}$.

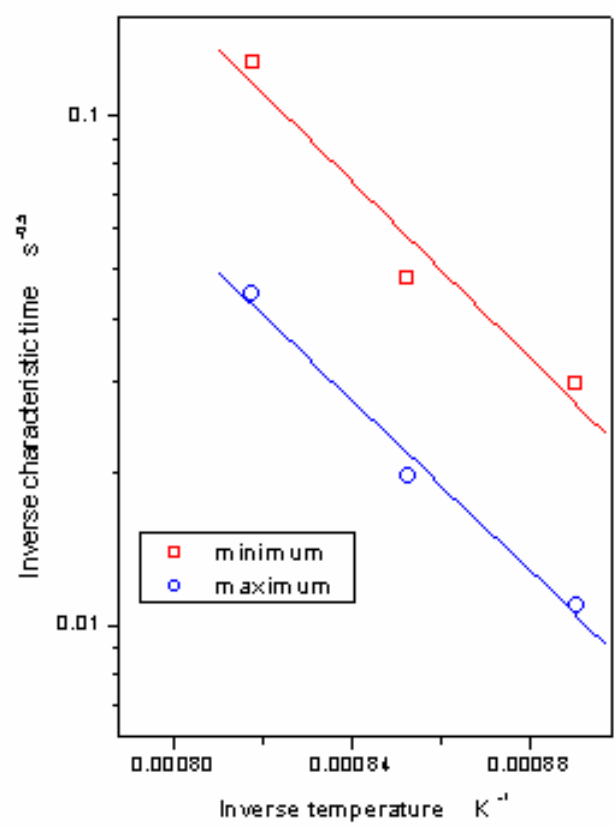

Fig 9 Temperature dependence of characteristic times in Nimonic 90 oxidation experiments. 


\section{References}

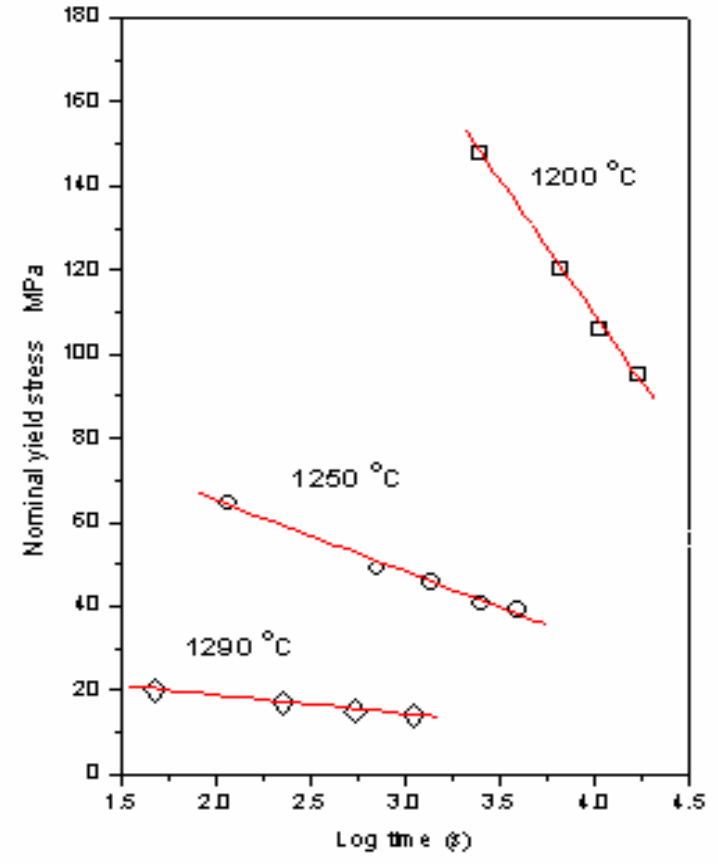

Fig 10 Time dependence of yield stress in multihit recrystallisation tests.

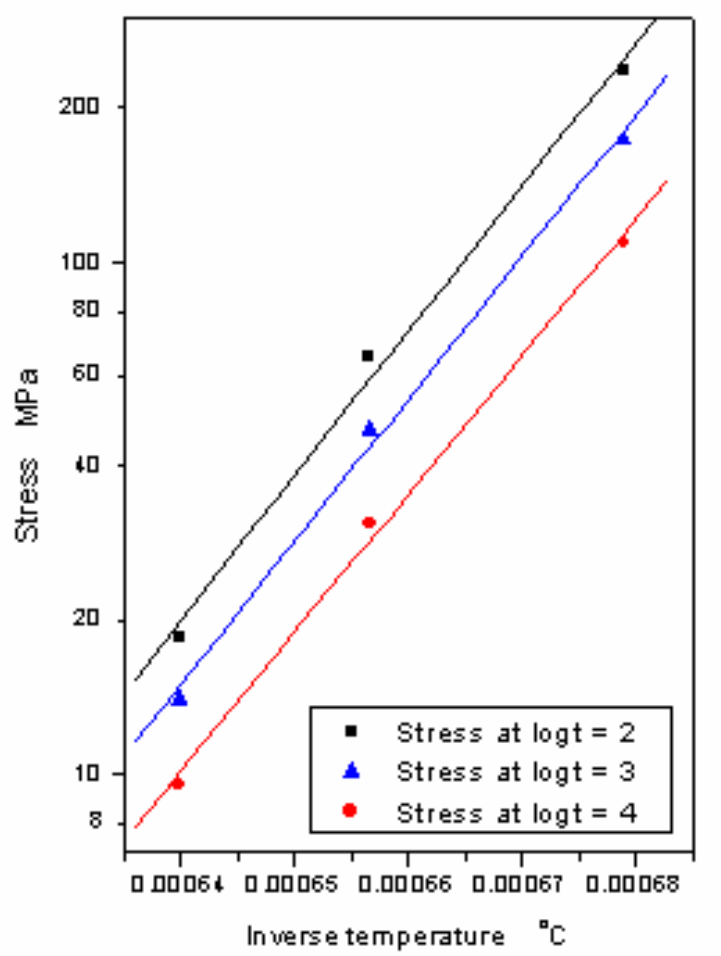

Fig 11 Inverse temperature dependence of recrystallisation flow stress.
1. B Roebuck, D C Cox and R C Reed. The Temperature Dependence of $\gamma^{\prime}$. Volume Fraction in a Ni Base Single Crystal Superalloy from Resistivity Measurements, Scripta Mater., 44, (2001), 917-921.

2. D C Cox, B Roebuck, C M F Rae and R C Reed. Recrystallisation of Single Crystal Superalloy CMSX-4. Mater. Sci. and Techn., 19, 2003, 440-446.

3. M S Lewandowski and R A Overfelt. Acta Mater., 47(18), 1999, 4695-4710.

4. B. Roebuck, L P Orkney and J D Lord. Validation of a Miniature Tensile Strength Measurement System. ASTM $4^{\text {th }}$ Symposium on Small Specimen Test Techniques, STP 1418, Eds M A Sokolov, J D Landes and G E Lucas, Reno, Nevada, January 23-25, 2001, 234-250.

5. J S Perttula and L P Karjalainen. Recrystallisation Rates in Austenite Measured by Double Compression and Stress Relaxation Methods. Mater. Sci. and Techn., 1998, 14, 626-630.

6. Per Kofstad. High Temperature Corrosion, Elsevier, 1988, p 401.

\section{Acknowledgements}

Part of this work was performed with the support of the UK Department of Trade and Industry Measurement Programme on the Processability of Materials. The authors would like to thank NPL colleagues M Brooks and M G Gee for collaboration with the development of the ETMT and the Labview program for control. R C Reed acknowledges funding from the Natural Sciences and Engineering Research Council of Canada. 